\title{
DESIGN PARA A SUSTENTABILIDADE E A RELAÇÃO HISTÓRICA DAS EMBALAĢENS COM QUESTÕES AMBIENTAIS
}

\author{
Dulce de Meira Albach, Me. (UFPR); \\ Dalton Luiz Razera, Dr. (UFPR); \\ Jorge Lino Alves, Dr. (Universidade do Porto).
}

PALAVRAS CHAVE

Design para a Sustentabilidade; Embalagem; Alimentos; História

KEY WORDS

Design for Sustainability; Packaging; Food; History

\section{RESUMO}

Este artigo apresenta parte da pesquisa que aborda o Design para a Sustentabilidade voltado ao setor de embalagens de alimentos em autosserviço - especificamente em supermercados. No processo de análise da forma de funcionamento do referido setor e segmento, elaborou-se um levantamento, em fontes bibliográficas, de embalagens e/ou formas de embalamento em diferentes períodos da história da humanidade. Em paralelo a este, foi realizado um levantamento de preceitos ambientais e/ou de sustentabilidade. Constatou-se, entre outros fatores, o aumento exponencial do volume de embalagens ao longo das décadas em associação ao aumento da população nos meios urbanos. Consequentemente houve o aumento da demanda por alimentos e estes por sua vez requisitando soluções de embalamento. No processo de reconhecimento de influências recíprocas entre as questões ambientais e as embalagens, concluiu-se que até o momento atual o desenvolvimento destas não reflete em igual qualidade naquela em termos de sustentabilidade.

\begin{abstract}
This article presents part of a research that addresses the Design for Sustainability focused on the sector of food packaging in self-service - specifically in supermarkets. During the analyses process of the referred sector and segment's way of work, a search for bibliographical sources of packaging and/or forms of packaging, in different periods of history has been drawn up. Parallel to this, a survey of environmental requirements and/or sustainability was conducted. It found, among other factors, the exponential increase in the volume of packaging over the decades, in association with population increase in urban areas. Consequently, there was an increase in food demand, which in turn demands packaging solutions. In the process of reciprocal influences recognition, between environmental issues and packaging, it has been concluded that up to the present moment the development of these does not reflect in equal quality in that in terms of sustainability.
\end{abstract}




\section{INTRODUÇÃO}

O processo de desenvolvimento econômico e a crescente concentração da população em áreas urbanas são fatores que modificam constantemente o comportamento humano e o cenário de produção de bens de consumo e serviços. Neste contexto, a indústria de alimentos é um dos segmentos pressionados para a produção de soluções que abasteçam a população em larga escala.

Esta indústria está diretamente atrelada à indústria de embalagens. Ambas se encontram em intenso desenvolvimento e produção e atuam de forma conjunta, pois os produtos alimentícios demandam sistemas de embalamento adequados, seja na fase de produção, de transporte, de distribuição, de venda ao consumidor, bem como, da forma de utilização.

Um fato de grande destaque e interferência neste processo é o surgimento do "supermercado" na década de 1930 nos Estados Unidos ou na década de 1950 no Brasil. Este sistema de venda, denominado de "autosserviço", obrigou a uma completa reformulação na função das embalagens que se transformou em ícone da cultura de massa. Além de proporcionar proteção aos produtos embalados, a nova forma de expor o produto, sem a presença de um balconista, requereu que as embalagens também se autovendessem e explicassem seus conteúdos (CAVALCANTI e CHAGAS, 2006).

No entanto, o suprimento desta demanda promove um aumento significativo da composição média de resíduos que denotam, atualmente, uma desproporcionalidade entre seu volume e a capacidade de um gerenciamento adequado em termos de assimilação ambiental (DIAS, 2002; MENEGAT et al., 2004, STEWART, 2010; WALDMAN 2012).

Diante destas constatações, este trabalho apresenta parte da pesquisa que aborda o Design para a Sustentabilidade voltado ao setor de embalagens de alimentos em autosserviço - especificamente em supermercados - na qual elaborou-se uma análise comparativa, por meio de fontes bibliográficas, entre a evolução das embalagens e/ ou processos de embalamento e as questões ambientais e/ou de sustentabilidade, ao longo da história da humanidade.

\section{EMBALAGENS E MEIO AMBIENTE NOS PERÍODOS HISTÓRICOS}

A análise aqui apresentada é subdividida nos períodos denominados de Pré-História, Idade Antiga, Idade Média, Idade Moderna e Idade Contemporânea. Para cada um foram estabelecidas comparações entre embalagens e meio ambiente, formalizando embasamentos para possíveis atitudes futuras diante do aprendizado pelo passado.

\subsection{Pré-História}

Partindo-se inicialmente da observação do período da Pré-História, aproximadamente 50.000 AEC a 3.000 AEC, constata-se que apenas a natureza era fonte de recursos. As necessidades de guardar ou transportar alimentos e objetos era suprida, por exemplo, com chifres ocos, crânios de animais, folhas e troncos de árvores, grandes conchas, ou bexiga de animais (ENDLER, 2015; CINTRA, 2015).

Naquela época, o período da humanidade caracterizado pelo Paleolítico ou Idade da Pedra Lascada (aproximadamente $30.000 \mathrm{AEC}$ ) é frequentemente descrito como de nomadismo e uma rudimentar divisão de tarefas, principalmente de caça, pesca e coleta. O período subsequente, o Neolítico ou Idade da Pedra Polida (aproximadamente 4.000 AEC), é marcado por sociedades mais sedentárias a partir de certo domínio sobre técnicas agrícolas e da criação de animais, dando origem a formação dos primeiros núcleos urbanos. Com isto, apareceram atividades como o artesanato e o comércio, modificando o modo de vida estritamente rural.

A cerâmica também é uma descoberta ocorrida provavelmente pouco depois que o homem descobriu o fogo e percebeu que a ação das chamas era capaz de endurecer o barro. Esta é uma das primeiras intervenções do homem por meio da transformação físico-química de elementos naturais. Estudos arqueológicos supõem que é do Período Neolítico o surgimento da cerâmica utilitária, pois como os humanos passaram a cultivar a terra, precisavam de "embalagens" para guardar os mantimentos.

Observa-se do período em questão que os resíduos produzidos pelo homem eram essencialmente compostos por matéria orgânica caracterizados por uma fácil decomposição.

\subsection{Idade Antiga}

A denominada Idade Antiga ou Antiguidade (3.000 AEC a 476), segundo Sousa (2015), é marcada pelo desenvolvimento do Mundo Oriental (via as civilizações Chinesa, Indiana, Egípcia e dos vários povos que dominaram a região da Mesopotâmia), do Mundo Ocidental (com destaque para a civilização Greco-Romana) e dos Maias, Astecas, Incas e Olmecas no Continente Americano.

Um fator em comum que se observa, genericamente, com relação às embalagens neste período, é que estas se destinavam a proteger e conservar os produtos de consumo diário. Se caracterizavam por utensílios fabricados manualmente e em diferentes tipos de materiais. Gombri 
ch (1993, p. 50) por exemplo, em análise à arte cerâmica egípcia esclarece que "...estes recipientes pintados, conhecidos pelo nome genérico de vasos, destinavam-se mais amiúde a conter vinho ou azeite do que flores".

Além deste fato, este período é marcado também pelo surgimento de embalagens com conceito de conter para transportar e armazenar, com finalidades comerciais, em função do intercâmbio de mercadorias entre a Mesopotâmia e o Egito. Os produtos eram acondicionados a granel e embarcados em navios em contentores de argila e fibras naturais. $\mathrm{O}$ aumento do transporte de produtos promove a necessidade de evitar perdas e contaminações. São criados os precursores do barril e conceitos de recipientes fechados e lacrados (ENDLER, 2015).

Como exemplos pode-se também destacar as peças polidas com finalidade utilitária das Civilizações PréColombianas; a cerâmica refinada na China; e as embalagens tradicionais do Japão feitas com produtos naturais como madeira, bambu, palha, papel, tecido e cerâmica.

Quanto às questões ambientais constata-se que na Antiguidade os recipientes serviam para conservar e facilitar a utilização sem perder suas características após o consumo, configurando um processo de reutilização.

\subsection{Idade Média}

Na passagem para a Idade Média (476 a 1453), uma figura destacada por Fernandes (2015), mais especificamente nos séculos XIII e XIV, é a do mercador que surge neste momento de desenvolvimento do comércio e se encontra no centro das relações que se travavam nos espaços comerciais dos burgos (primeiras cidades que comportavam o intenso fluxo de pessoas e de mercadorias). Nestes, responsabilizava-se pela mediação entre os produtos que vinham de outros continentes e os compradores das feiras medievais. Alguns historiadores assinalaram que, ao lado dos humanistas, os mercadores foram os grandes responsáveis pela 'construção da Idade Moderna' e que seu conhecimento e suas habilidades favoreceram a ascensão da nova classe que viria a ser protagonista: a burguesia.

Na segunda metade da Idade Média (meados do século XIII) ocorreu a decadência do feudalismo em função da revolta dos camponeses até então explorados pelos senhores feudais, pelos reis e pela igreja. Os camponeses então na miséria foram atraídos para os centros urbanos que apresentavam uma expansão de suas atividades, principalmente do artesanato e do comércio. Surge assim duas novas classes sociais: a burguesia comercial e o trabalhador assalariado, fato este denominado como o do surgimento do capitalismo.
Outro fato importante do período foi o dos Árabes capturarem fabricantes Chineses de papel a partir de fibra de linho e aprenderem o processo. Desta forma o papel foi difundido na Europa, Ásia e posteriormente na América, caracterizando, também, um novo mercado para embalagens (BERGER e WELT, 2005). Novas técnicas de explorar o vidro também se sobressaem. Este fato pode ser observado em Manzini (1993, p. 172) ao afirmar que "Já por volta de 1300, os vidreiros de Murano eram capazes de produzir uma gama sofisticada de tonalidades e tinham aperfeiçoado um método de fabrico de um vidro excepcionalmente límpido com superfícies brilhantes, a que chamaram 'cristal' ".

Pode-se constatar neste período em questão que houve um amadurecimento dos processos artesanais de fabricação de embalagens, bem como a continuidade da característica de reutilização das mesmas após cada consumo do produto embalado. Por outro lado, o crescimento das cidades proporciona o consequente aumento da geração de resíduos.

\subsection{Idade Moderna}

O advento das grandes navegações, entre outros fatos, vai marcar o início da Idade Moderna (1453 a 1789), o que além de contribuir para o acúmulo de capitais na Europa, também foi importante para a dinâmica de um comércio de natureza intercontinental - descoberta do 'novo mundo', o continente Americano (SOUSA, 2015).

Este período da história ficou conhecido como Renascimento e no qual a humanidade deu grandes saltos em várias áreas do conhecimento. $\mathrm{O}$ contato entre culturas também foi um fator que favoreceu, por exemplo, o desenvolvimento de novos tipos de embalagens, tanto pelo aparecimento de novos itens de troca e consumo como pela necessidade de conservar os produtos por mais tempo. "Curiosamente, os períodos de guerra viabilizaram o desenvolvimento de embalagens de vidro e metais devido à necessidade estratégica de transporte e conservação de alimentos para tropas de exército, já que prover comida naquelas condições era um grande desafio" (CINTRA, 2015).

Em termos ambientais, a humanidade ainda acreditava que os recursos naturais, como água e ar, eram infinitos e que a natureza absorveria os lixos produzidos (GORE, 1993). No entanto, a proliferação de epidemias dizimando milhões de pessoas, foi um alerta importante para a necessidade de tratar e destinar adequadamente o aumento do lixo (MELOSI, 2005). Associa-se desta forma o inchamento das cidades à insalubridade. 


\subsection{Idade Contemporânea}

Para facilitar a exploração dos acontecimentos pesquisados na Idade Contemporânea, seu conteúdo foi dividido em três partes. A primeira representa o período compreendido entre 1789 a 1918, a segunda parte de 1918 a 1945 e a terceira de 1945 aos dias atuais.

\subsubsection{Idade Contemporânea - Parte 1}

A 1a Revolução Industrial (Inglaterra - carvão e ferro - 1780 a 1850) com o desenvolvimento de novas máquinas e instrumentos na Inglaterra vai marcar o fim da Idade Moderna e início da Idade Contemporânea. As atividades consideradas "naturais" como a agricultura, a pecuária, a pesca e a mineração, foram mais intensamente suplantadas pela produção industrial e o capitalismo. Novas mudanças surgem e se refletem até a atualidade.

Em 1789 ocorre a Revolução Francesa, com a tomada de poder pela burguesia. Neste momento, os avanços tecnológicos permitiram produzir cada vez mais a custos baixos e o que se produzia, vendia. No entanto, com a evolução das técnicas, aumenta a oferta e a concorrência e os bens de consumo não se escoam mais naturalmente. O consumidor também fica mais exigente quanto a qualidade e segurança das mercadorias. Inicia-se a preocupação com o aspecto mercadológico da embalagem e surgem as primeiras legislações sobre $o$ assunto.

Neste contexto recebem destaque os estudos de Thomas Malthus (1789) discutindo o crescimento populacional desenfreado; os de Thomas Huxley (1862) tratando das interdependências entre os seres humanos e os demais seres vivos; ou os de George Perkins Marsh (1864) expondo as questões de degradação do planeta e analisando as causas do declínio de civilizações antigas, prevendo o declínio das civilizações modernas, caso não houvesse mudanças (DIAS, 2002).

Refletindo esta situação inicia-se a criação de sociedades de proteção à natureza, parques e reservas nos EUA, Canadá, Chile, Porto Rico, Uruguai entre outros países, pois a poluição passou a figurar (obviamente não apenas em função das embalagens) como um fator de destaque no processo chamado de "desenvolvimento".

Buscando melhorias ambientais, surgiram obras efetivas de saneamento básico como: sistemas de esgoto, usinas de tratamento de detritos e reutilização da lama dos esgotos na agricultura. Consequentemente os hábitos domésticos sofreram mudanças buscando minimizar o mau cheiro e o risco de poluição, embora ainda de forma ineficiente diante do rápido aumento populacional (MELOSI, 2005).

$\mathrm{Na}$ concepção das embalagens observa-se que num primeiro momento eram voltadas para a distribuição e conservação dos produtos a granel e em longas distâncias. Estes produtos eram estocados pelos varejistas o que fazia com que os consumidores tivessem que utilizar suas próprias sacolas ou sacos de papel. Um exemplo de 1899 que sinaliza uma mudança deste contexto é a embalagem do biscoito Uneeda dos EUA, considerado o primeiro a ser vendido em embalagem tipo cartucho com os biscoitos envoltos internamente por um papel (Figura 1).

Figura 01 - Anúncio do biscoito Uneeda

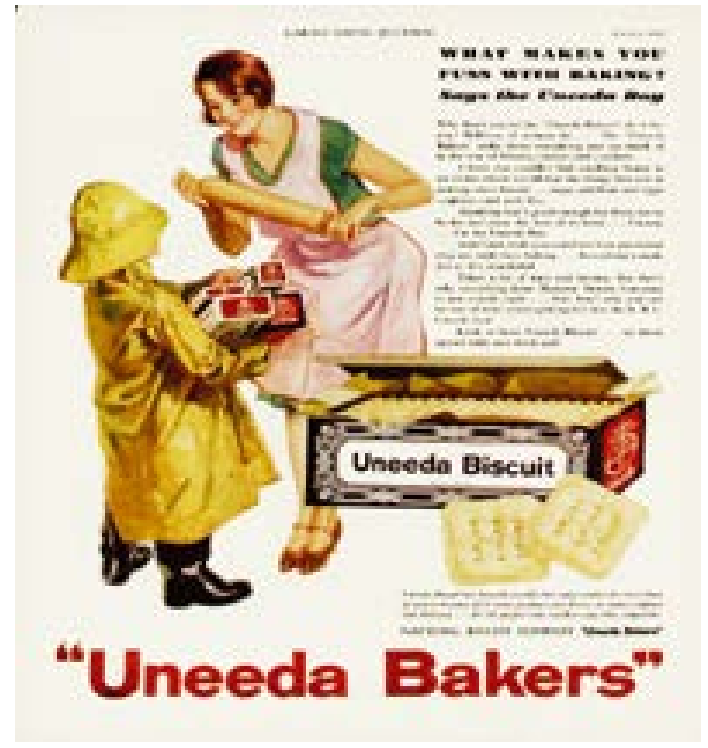

Fonte: issu.com (2015)

Com relação ao Brasil, a vinda de D. João VI (fugido de Portugal para não atender as determinações de Napoleão Bonaparte no sentido de cortar vínculos econômicos com a Inglaterra), em 1808, refletiu num grande aumento do fluxo de manufaturas chegando no Rio de Janeiro. Entre as importações destacam-se as bebidas alcoólicas como vinho, licores e cervejas. Este fato impulsionou a fundação das primeiras fábricas de garrafas e garrafões de vidro no país, para que as bebidas recebidas em barris fossem transvasadas para as garrafas de produção local. Além de diversos tipos de garrafas, estas fábricas começaram a produzir também compoteiras e frascos para remédios e perfumes.

$\mathrm{Em}$ termos de produção local (brasileira), outro destaque é para as caixas de madeira para exportação de açúcar, sucedidas pelos sacos de juta para a exportação de café. Gradativamente, e acompanhando o processo de 
industrialização, a produção de embalagens vai saindo da categoria de artesanato e o país de produtor exclusivamente agrícola. Observa-se o surgimento da sacaria de algodão para os moinhos de trigo, a lataria de metal para produtos alimentícios, os vidros para os remédios e perfumes, as garrafarias para cerveja, o papel para os cigarros e embrulhos, o papelão para todos os tipos de caixas (CAVALCANTI e CHAGAS, 2006).

Nesta atmosfera de desenvolvimento industrial, a Primeira Guerra Mundial (1914 - 1918), paradoxalmente, representou uma grande oportunidade de fortalecimento do produto nacional brasileiro que, com a diminuição drástica do transporte marítimo, viu-se livre da concorrência inglesa. Novas empresas são fundadas, principalmente por imigrantes, e um fato em comum é que estas tinham um setor de embalagens próprio para embalar seus produtos. Para estes compravam a matéria-prima (papel, madeira e folha-de-flandres) e imprimiam rótulos, fabricavam caixas e latas.

Desta forma, embora ainda existisse a reutilização de embalagens de transporte, para as embalagens de consumo dá-se início aos produtos que não são mais vendidos apenas a granel. Este fato que por um lado visava a facilidade de comercialização, por outro refletia no descarte sem possibilidade de reutilização e consequentemente no surgimento de um novo tipo de resíduo.

\subsubsection{Idade Contemporânea - Parte 2}

Kazazian (2005) destaca que desde o fim da $1^{\text {a }}$ Guerra Mundial a produção industrial conheceu uma vitalidade sem precedentes. Esta é marcada pela chegada, por exemplo, de novos equipamentos como o automóvel e os eletrodomésticos. Este momento é estimulado pelos créditos ao consumo nos anos 1920. Porém, a volatilidade dos valores da Bolsa e a dicotomia entre a especulação e a realidade das operações econômicas refletiram no endividamento crescente, culminando com a denominada "Crise de 1929".

Esta crise levou a economia mundial a um período de deflação e uma queda industrial inédita. O cenário só mu-

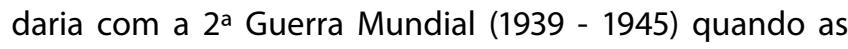
estratégias das empresas se redefiniram em função das expectativas de mercado. A estrutura da economia mundial se orientou para o consumo, que se expandiu durante a reconstrução. Dias (2002) ressalta que o intenso crescimento econômico promoveu a aceleração da urbanização e, com esta, o aumento da perda de qualidade ambiental começou a aparecer de forma mais evidente em diversas partes do mundo.

Com relação especificamente às embalagens, um fato da época em questão de extrema importância é o surgimento do supermercado. Este fato ocorreu nos EUA em 1930 com o King Kullen Grocery Company, em plenos efeitos da Crise de 1929. Eliminar balcões e balconistas era uma forma de economizar diante de um cenário de precariedade generalizada (CAVALCANTI e CHAGAS, 2006). Provavelmente não se imaginou, naquele momento, que este sistema de autosserviço, ou seja, um sistema no qual o próprio consumidor se servia dos produtos que pretendia comprar, se converteria posteriormente em forma padrão de facilitar a compra e a venda. E, também, no ambiente que promoveria (e promove até os dias atuais) imensas transformações na indústria de embalagens mundial, bem como soluções de embalamento.

Quanto a configuração das embalagens observase a comercialização de diversos tipos de termoplásticos como o Polietileno de Baixa Densidade, o Poliestireno e o PVC; as folhas de alumínio reconhecidas pela propriedade de barreira funcional (ex.: embalagens de bala); ou os barris de madeira para chopp substituídos pelos feitos de alumínio e aço inoxidável.

Nas décadas de 1930 e 1940 o Brasil foi palco da entrada das multinacionais, especialmente as de produtos de higiene e beleza, cujos critérios de qualidade e o interesse pela opinião do público revolucionaram a embalagem brasileira da época.

\subsubsection{Idade Contemporânea - Parte 3}

Foi na década de 1950 que surgiram os primeiros supermercados no Brasil (Figura 2) e com estes um amplo repensar das embalagens. Até esse momento, a venda de secos e molhados era dos empórios ou armazéns e as compras geralmente pagas no final do mês, via controle em uma caderneta (CAVALCANTI e CHAGAS, 2006).

Os supermercados mudam este cenário e a nova forma de comercialização apoiada no autosserviço vai, aos poucos, transformando a embalagem em um "vendedor silencioso" - expressão cunhada na década de 1960 pelo americano James Pilditch, autor do livro homônimo, para descrever o papel da embalagem no 'ponto-de-venda' (CALVER, 2009). Cabe a ela agora (a embalagem) desempenhar o papel antes feito pela figura do balconista - textos e imagens substituem a conversa do antigo vendedor e o pagamento é feito na hora. Segundo Caropreso e Gramani Filho (2008), 
Figura 02 - "Sirva-se" - primeiro supermercado do Brasil, em 1950
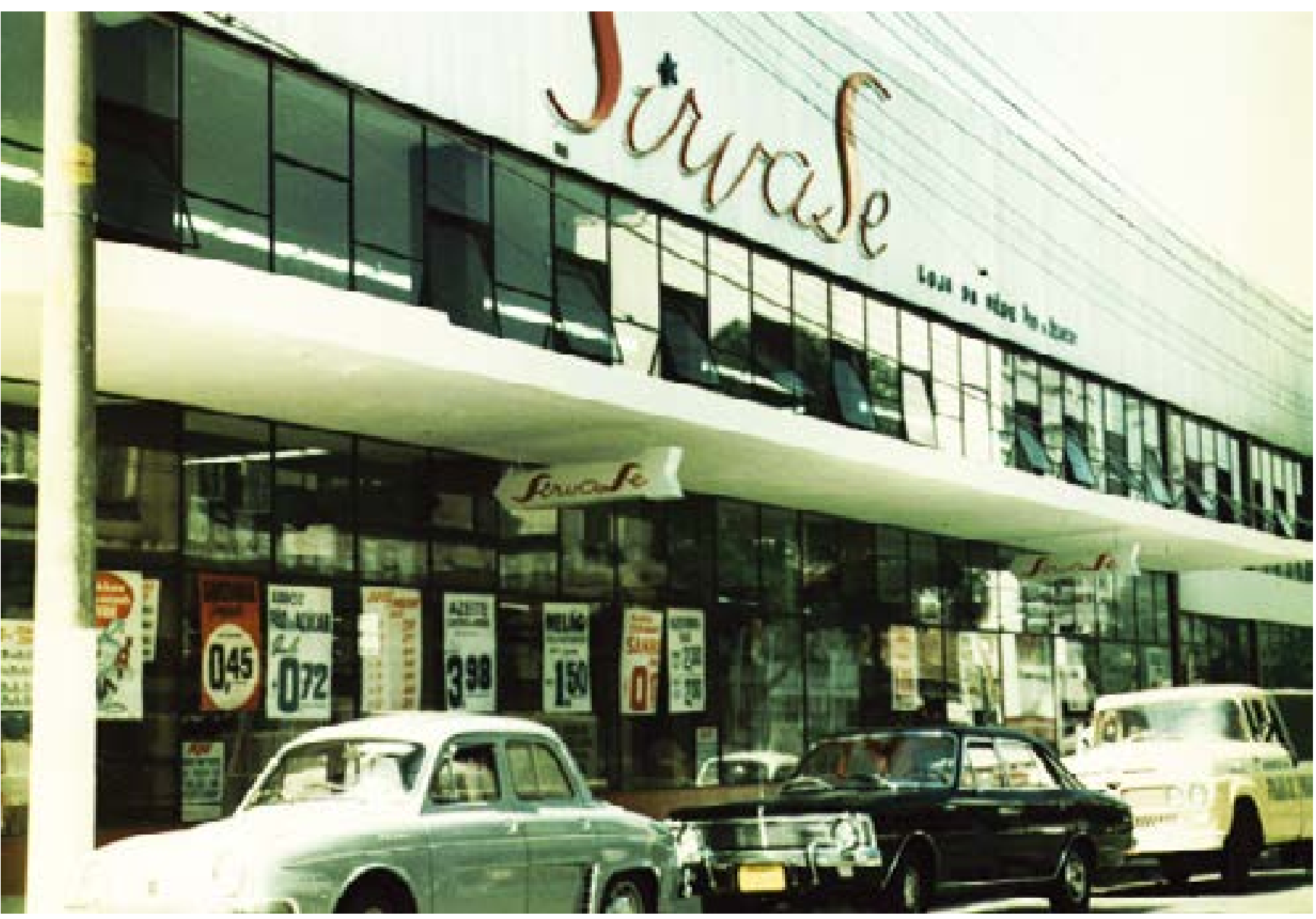

Fonte: GPA (2015)

os consumidores passaram a ser muito mais influenciados pela embalagem ou pela habilidade desta em chamar a atenção.

Outro fato de destaque, em meados de 1950, foi a denominada "Revolução Verde" caracterizada por uma mudança do padrão de produção agrícola, proporcionando expressivo aumento da oferta de alimentos. Impulsiona-se assim a crescente industrialização destes e a nova maneira de acondicioná-los. Isto implicou em ampliação da capacitação dos profissionais, em renovação de máquinas e equipamentos e no desenvolvimento de novos materiais e soluções de logística (SARANTÓUPOLOS e DANTAS, 2012).

Diante das embalagens de produtos semelhantes expostos lado a lado nas prateleiras dos supermercados, estabelece-se uma nova forma de concorrência na qual a embalagem vai adquirir maior importância no contexto de formação da marca e na interação do consumidor com o produto. Este fato também recebe influência da publicidade, apoiado pela televisão.
Contudo, é na década de 1980 que se verifica a maior introdução de todos os tempos de novos produtos/embalagens (GURGEL, 2014). Entre outros exemplos, pode-se citar as embalagens de plásticos flexíveis substituindo latas de metal, frascos de vidro e garrafas, visando a facilidade de utilização, economia e transporte; as embalagens de produtos congelados que ficaram mais seguras; as embalagens assépticas cartonadas; embalagens plásticas esterilizáveis; sistemas de refechamento e fácil abertura; ou embalagens com atmosfera modificada.

Especificamente com relação às questões ambientais o livro "Silent Spring" (Primavera Silenciosa) em 1962, de Rachel Carson é considerado um protagonista dos movimentos ambientalistas juntamente com o surgimento de ONGs - Organizações Não Governamentais como o WWF - World Wide Fund for Nature, Friends of the Earth e Greenpeace, trabalhando por mudanças de políticas e regulamentos governamentais. Este processo culmina com o surgimento do termo "Desenvolvimento Sustentável", em 1987, por meio do Relatório “Our Common Future” (Nosso 
Futuro Comum), também conhecido por Relatório Brundtland, elaborado pelo World Comission on Environment and Development.

A ONU - Organização das Nações Unidas também se destaca pela iniciativa de realizar conferências sobre o meio ambiente. Entre estas, recebeu grande destaque a Rio 92, no Brasil, com a participação de 170 países e onde foram discutidos e elaborados importantes documentos como a "Carta da Terra" e a "Agenda 21". O evento representou um marco na popularização dos conceitos de desenvolvimento sustentável e, a partir deste, consolida-se até a atualidade uma sucessão de encontros para discussões, proposições e acordos mundiais.

Na esfera do Design destacam-se, entre outros, os princípios para um design ecológico, aprovados na Assembleia Geral do ICSID - International Council of Societies of Industrial Design em 1993 em Glasgow, Escócia, que são: defesa de produtos e serviços seguros; uso sustentado e otimizado de recursos naturais; uso da energia com sabedoria; parâmetros de desempenho excepcionais; proteção da biosfera; projeto da fase pós-uso; redução do lixo e incremento da reciclagem. Os preceitos abordados e voltados à sustentabilidade denotam a necessidade de se projetar colocando o meio ambiente como uma preocupação desde o início do processo e estendendo as responsabilidade entre todos os stakeholders (MALAGUTI, 2001).

Em 1994 obteve destaque o estabelecimento do denominado, por John Elkington, "tripé da sustentabilidade", visando incitar as empresas a associarem às questões econômicas, às socias e ambientais (ELKINGTON, 2007). Neste sentido, Vezzoli (2010) explora a dimensão ambiental e associa à dimensão social, a ética e à dimensão econômica, a política.

É também na década de 1990 que recebe destaque o "LCD - Lyfe Cycle Design" (Design do Ciclo de Vida) ou "Ecodesign" que se caracteriza por um modelo que considera cada estágio do ciclo de vida do produto com o intuito de reduzir impactos ambientais adversos, associados a todos os outros critérios projetuais tradicionais como ergonômicos, funcionais e estéticos.

Pode-se considerar que o estágio de desenvolvimento do LCD está situado entre o "Green Design" e o "Design para a Sustentabilidade". O Green Design ocorreu mais acentuadamente na década de 1980 e a ênfase de projeto era para o redesign de um mesmo conceito e sem perspectiva de ciclo de vida. $E$, o Design para a Sustentabilidade, com ênfase a partir dos anos 2000, propõe uma mudança de paradigma com a atuação nas várias dimensões do desenvolvimento sustentável. Destacam-se assim abordagens como: responsabilidade social, eco-inovação, sistema produto-serviço, bem-estar humano, design estratégico, co-criação, mudança radical, para citar algumas. Para Manzini e Vezzoli (2005) o Design do Ciclo de Vida é uma metodologia indissociável do Design para a Sustentabilidade, por serem atividades que se complementam para o desenvolvimento de produtos e serviços sustentáveis.

Desta forma, o século XXI tem sido palco de propostas no setor de embalagens que denotam o repensar a forma de produção e consumo em prol de melhorias em questão de reflexos ambientais adversos. Dentre estas pode-se citar propostas de embalagens retornáveis; embalagens reutilizáveis; embalagens fabricadas exclusivamente com materiais recicláveis; simplificação dos processos de impressão; embalagens com materiais biodegradáveis; uso de refil; novos sistemas de comercialização com redução de embalagens; embalagens comestíveis; sistemas produto-serviço; entre outras.

No entanto, no âmbito destas proposições, muitas variáveis colocam em questionamento suas reais eficácias. No Brasil, por exemplo, a destinação de maior destaque enquanto planejamento ambiental para as embalagens ainda é a reciclagem. No entanto, apesar de avanços, os programas de coleta seletiva atuam apenas em $17 \%$ dos municípios do país (CEMPRE, 2015). Conclui-se desta forma, que o volume reciclado ainda corresponde a uma parcela mínima dos resíduos nacionais gerados.

Inserido neste contexto está a promulgação em 2010 do Plano Nacional de Resíduos Sólidos (PNRS), por meio da Lei $n^{\circ} 12.305 / 10$, que estabelece, entre outras prerrogativas, acabar com os lixões; implantar coleta seletiva em todos os municípios; implantar a logística reversa; e a compostagem dos resíduos úmidos. Premissas que se configuram, no atual momento, por grandes dificuldades e desafios para o poder público e para o setor privado do país.

\section{CONSIDERAÇÕES FINAIS}

No acompanhamento do referencial histórico aqui apresentado, observa-se entre outros fatores, o aumento exponencial do volume de embalagens ao longo das décadas. Intrinsecamente relacionado está o fato do aumento da população nos meios urbanos e o consequente aumento da demanda por alimentos, estes por sua vez, requisitando soluções de embalamento.

Fator de destaque, no escopo desta pesquisa, é o surgimento dos supermercados mudando a forma de comercialização e atribuindo à embalagem a denominação 
de "vendedor silencioso" em função das características do autosserviço. Este processo vai denotar a crescente introdução de novos produtos e embalagens, acompanhados pelo desenvolvimento da indústria de materiais e processos, criando uma relação de reciprocidade num mercado cada vez mais competitivo e exigente.

Com relação às questões ambientais, demonstradas de forma paralela nesta pesquisa histórica de embalagens, pode-se observar que a evolução desta não refletiu em igual qualidade naquela. De resíduos essencialmente orgânicos e de característica como a reutilização, a civilização humana passou a conviver com um volume desproporcional de outros resíduos - os industrializados.

Apesar de alguns cientistas e pensadores terem chamado a atenção para os problemas de crescimento populacional e a relação com a natureza, é apenas a partir de meados da década de 1940 que se verifica o crescimento de movimentos ambientalistas, além de publicações e eventos, com denúncias, proposições e intenções de acordos mundiais, diante do grave cenário de poluição. Embora não apenas as embalagens digam respeito a estes movimentos, elas são importantes representantes do capitalismo desenfreado e, muitas vezes, impensado.

Sendo assim, no final da década de 1990, os preceitos abordados e voltados à sustentabilidade denotam a necessidade de se projetar colocando o meio ambiente como uma preocupação desde o início do processo e estendendo as responsabilidades entre todos os stakeholders. Surgem então propostas de embalagens retornáveis, reutilizáveis, refis, materiais biodegradáveis, entre alternativas, em prol da melhoria de reflexos ambientais adversos.

Observa-se em termos gerais que as implicações ainda são imensas no sentido de sincronizar a forma de atuação da indústria de embalagens e de alimentos e a forma de consumo, com preceitos próximos de melhor sustentabilidade.

O surgimento do conceito de "Design para a Sustentabilidade" fundamentado pela metodologia do Design do Ciclo de Vida estabelece uma mudança de paradigma e uma visão que se desloca, mais amplamente, do artefato para o sistema de produção e consumo, e este associado ao design estratégico. Desta forma, vislumbram-se cenários futuros que possam alcançar uma maior sustentabilidade em amplo sentido.
2. CALVER, Giles. O que é design de embalagem? / Giles Calver; tradução: Edson Furmankiewicz. Porto Alegre: Bookman, 2009.

3. CAROPRESO, Luiz; GRAMANI FILHO, Plínio (Coord.) 200 anos: indústria gráfica no Brasil / projeto geral: Associação Brasileira da Indústria Gráfica (ABIGRAF); edição de texto: Ricardo Viveiros. São Paulo: Clemente e Gramani Editora, 2008.

4. CAVALCANTI, Pedro; CHAGAS, Carmo. História da embalagem no Brasil. São Paulo: Grifo Projetos Históricos e Editoriais, 2006.

\section{CEMPRE - Compromisso Empresarial para a Reciclagem.} Ciclosoft 2014. Radiogafando a coleta seletiva. Disponível em: <http://cempre. org.br/ciclosoft/id/2>. Acesso em 06 nov. 2015.

6. CINTRA, Lydia. Como nasceram as embalagens. Super Interessante. Disponível em: <http://super. abril.com.br/blogs/ideiasverdes/como-nasceram-as-embalagens/>. Acesso em 06 nov. 2015.

7. DIAS, Genebaldo Freire. Pegada Ecológica e Sustentabilidade Humana. São Paulo: Gaia, 2002.

8. ELKINGTON, John. Brundtland and sustainability: history's balance-sheet. Open Democracy, 2007. Disponível em: <https:// www. opendemocracy.net/globalization-institutions_go vernment/sustainability_4521.jsp>. Acesso em 20 nov. 2015.

9. ENDLER, Danilo. A história e a embalagem. Disponível em: topdeembalagem.com.br/index.php?botao $=5 \&$ subbot $=2 \&$ re$\mathrm{f}=1$ \&titulo=A\%20Hist $\%$ C3\%B3ria\%20e\%20a\%20

\section{REFERÊNCIAS}

1. BERGER, Kenneth R.; WELT, Bruce. A brief history of packaging. IFAS, University of Florida, ABE321, p. 1-5, 2005. Disponível em: $<$ http://ufdc.ufl.edu/IR00001524/00001>. Acesso em 06 nov. 2015. 